\title{
Review
}

\section{Novel therapies for epilepsy in the pipeline}

Boulenouar Mesraouaa, ${ }^{*}$, Dirk Deleua, Dimitri M. Kullmannb, Ashok K. Shettyc, Paul Boond, Emilio Peruccae, Mohamad A. Mikatif, Ali A. Asadi-Pooyag,h

a Hamad Medical Corporation and Weill Cornell Medical College-Qatar, Doha, Qatar

b UCL Institute of Neurology, University College London, United Kingdom

c Institute for Regenerative Medicine, Department of Molecular and Cellular Medicine, Texas A\&M University College of Medicine, College Station, TX, USA

d Reference Center for Refractory Epilepsy, Ghent University Hospital Belgium - Academic Center for Epileptology, Heeze-Maastricht, the Netherlands

e Unit of Clinical and Experimental Pharmacology, Department of Internal Medicine and Therapeutics, University of Pavia, and Clinical Trial Center, IRCCS Mondino Foundation, Pavia, Italy

$f$ Division of Pediatric Neurology and Developmental Medicine, Duke University Medical

Center, Durham, USA

g Shiraz Medical School, Shiraz University of Medical Sciences, Shiraz, Iran

n Jefferson Comprehensive Epilepsy Center, Department of Neurology, Thomas Jefferson

University, Philadelphia, USA

\section{${ }^{*}$ Corresponding author.}

E-mail addresses:

boulenouar.mesraoua@wanadoo.fr (B. Mesraoua),

ddeleu@hamad.qa (D. Deleu),

d.kullmann@ucl.ac.uk (D.M. Kullmann),

shetty@medicine.tamhsc.edu (A.K. Shetty),

paul.boon@ugent.be (P.Boon),

perucca@unipv.it (E. Perucca),

mohamad.mikati@duke.edu (M.A. Mikati),

aliasadipooya@yahoo.com (A.A. Asadi-Pooya). 


\begin{abstract}
Despite the availability of many antiepileptic drugs (AEDs) (old and newly developed) and, as recently suggested, their optimization in the treatment of patients with uncontrolled seizures, more than $30 \%$ of patients with epilepsy continue to experience seizures and have drug-resistant epilepsy; the management of these patients represents a real challenge for epileptologists and researchers. Resective surgery with the best rates of seizure control is not an option for all of them; therefore, research and discovery of new methods of treating resistant epilepsy are of extreme importance. In this article, we will discuss some innovative approaches, such as P-glycoprotein (P-gp) inhibitors, gene therapy, stem cell therapy, traditional and novel antiepileptic devices, precision medicine, as well as therapeutic advances in epileptic encephalopathy in children; these treatment modalities open up new horizons for the treatment of patients with drug-resistant epilepsy.
\end{abstract}

\title{
1. Introduction
}

For decades, the epilepsy community has addressed the burden of drug-resistant epilepsy by focusing on the development of new antiepileptic drugs (AEDs) and advancing epilepsy surgery techniques. These approaches have resulted in some success, but the percentage of patients with drug-resistant epilepsy has not changed substantially. More than $30 \%$ of individuals with epilepsy have persistent seizures despite the use of appropriate therapies, i.e., they have drug-resistant epilepsy [1-3]. Therefore, investigating and discovering new ways and strategies to treat epilepsy is of paramount significance. There are multiple approaches in the pipeline to treat drug-resistant epilepsy. In this article, we are going to discuss some of the interesting and innovative approaches, which are potentially opening new horizons in treating patients with drug-resistant epilepsy. We have to mention that many of these plausible strategies need to be validated and should be tested in large double-blind randomized clinical trials.

\section{P-glycoprotein inhibitors}

One of the mechanisms that has been put forward in drug-resistant epilepsy is removal of AEDs from the epileptogenic tissue through excessive expression of multidrug efflux transporters such as P-glycoproteins [P-gp; the encoded product of the human multidrug resistance-1 (MDR-1; ABCB1) gene] [4]. It has been shown that MDR-1 is overexpressed, and there is overactivity of $\mathrm{P}$-gp in brain tissue of rats and humans with drug-resistant temporal lobe epilepsy (TLE) [5-7]. It is proposed that P-gp is overexpressed at the luminal side of the brain capillary endothelial cells, where it acts as an efflux pump to lower the interstitial concentration of AEDs in the vicinity of the epileptogenic tissue and thereby render the epilepsy resistant to treatment with AEDs [4-8].

Hypothetically, adjunctive use of a P-gp inhibitor can be used to counteract drug resistance and could be efficacious in decreasing seizure frequency in patients with drug-resistant epilepsy [9]. In an open-label pilot study, Asadi-Pooya and coworkers investigated 19 adult patients with drug-resistant TLE [10]. Baseline seizure type and seizure count were determined. Patients were divided randomly into two groups. Group A received verapamil, 
P-gp inhibitor, $120 \mathrm{mg}$ per day $(n=13)$ and group B received $240 \mathrm{mg}$ a day $(n=6)$ in addition to background AEDs. All patients were followed for eight weeks. The proportion of responders, i.e., patients with at least a $50 \%$ reduction in seizure frequency from baseline, was tabulated. Seven patients (36.8\%) were responders, including three patients (50\%) in group B, two of whom achieved seizure freedom. Four patients $(30.7 \%)$ in group A responded favorably to verapamil [10]. Because of the lack of placebotreated control group, however, no definite conclusions can be drawn from this study.

Several AEDs frequently used in the treatment of epilepsy are substrates of P-gp both in rodents (gabapentin, lamotrigine, phenobarbital, phenytoin, and topiramate) and in humans (phenytoin, phenobarbital, lamotrigine, and levetiracetam) [11]. Adjunctive use of P-gp inhibitors in patients with drug-resistant epilepsy is an interesting approach that requires testing in well-controlled studies. Several compounds already in clinical use, including verapamil, nifedipine, quinidine, amiodarone, nicardipine, quinine, tamoxifen, and cyclosporin A are able to inhibit P-gp [12]. Identifying an optimal P-gp inhibitor that is potent, efficacious and well-tolerated, in patients with drug-resistant epilepsy who are taking specific AEDs, is desirable.

\section{Gene therapy}

Focal epilepsy is more likely to be drug-resistant than idiopathic generalized epilepsy. This means that treatments targeted to the epileptogenic zone could, in principle, overcome some of the limitations of small molecules that are not selective for the epileptic tissue. Of the region-targeted treatments that have been proposed are intracranial electrical or transcranial stimulation, local drug delivery, cooling devices, cell transplant, and gene therapy. Gene therapy has the theoretical advantage that it can achieve selective manipulation of neuronal or circuit excitability targeted to specific populations of neurons within a confined region of the brain. The following section reviews some of the gene therapy strategies that have shown promise in preclinical models.

Several important considerations need to be taken into account in developing gene therapy for clinical translation, namely the choice of viral vector, promoter, and transgene [13].

With respect to the viral vector, the overwhelming majority of current clinical trials of gene therapy for other Central Nervous System (CNS) diseases rely on adeno-associated viral vectors (AAVs) to deliver genes to neurons. These are replication-incompetent viral particles derived from viruses that are not known to be associated with any human pathology. Many types (especially AAV1, AAV2, AAV5, AAV8, and AAV9) are able to infect neurons. They differ with respect to their ability to spread within the tissue where they are injected. There has been considerable recent interest in an engineered capsid that confers the ability to cross the blood-brain barrier, in principle allowing systemic delivery [14]. However, this was achieved through a process of directed evolution in a mouse strain, and considerable further work would be required to develop a similar variant for use in humans. Thus, for the foreseeable future, AAVs will need to be injected directly into the brain parenchyma. Other viral vectors have been tested in the past. Neither adenovirus nor herpes simplex is likely to be suited for use in epilepsy, but retroviruses such as lentivirus (derived from human immunodeficiency virus (HIV)) shares with AAV the ability to infect neurons and lead to stable expression of transgenes. Lentiviral vectors (lentivectors) are Ribonucleic acid (RNA) 
viruses that contain the reverse transcriptase gene, and the transgenes can integrate in the host genome. This raises the theoretical risk of disrupting oncogenes. However, this is unlikely to be a limitation to the use of lentivectors in the CNS because neurons are postmitotic. It is, furthermore, possible to reduce the risk of insertional mutagenesis by using an integrationincompetent variant [15]. Lentivectors have the advantage over AAV that they have a larger packaging capacity, allowing larger genes to be included, or with larger regulatory elements.

As for promoters, different viral vectors have different intrinsic tendencies to infect subtypes of neurons and glia, but these on their own do not allow highly specific cell types to be targeted. The optimal promoter would also achieve a level of expression of the transgene that is sufficient to achieve a moderate alteration in cell properties without toxicity that can arise from endoplasmic reticulum stress. There have been several advances in identifying neuron-type specific promoters. The Calcium/calmodulin-dependent protein kinase II (CamKII) promoter can be packaged in an AAV or lentivector and biases expression towards forebrain excitatory neurons, and is therefore suitable for therapies that aim to manipulate the excitability of pyramidal neurons in the neocortex and hippocampus, granule cells of the dentate gyrus, and other excitatory principal cells. Targeting inhibitory interneurons has, until recently, been difficult because the promoters specific for GammaAminobutyric Acid (GABAergic) neurons are large or poorly defined. Nevertheless, the mDlx synthetic enhancer-promoter construct shows promise in mice [16].

With respect to transgenes, the gene therapies that have been reported in preclinical trials have generally been designed rationally, in the sense that they build on the simple hypothesis that the excitation-inhibition balance is disrupted in epilepsy. They can be broken down into several general principles:

(i) Neuropeptide overexpression. Several neuropeptides have inhibitory effects on neurons, acting through $\mathrm{G}$ protein-coupled receptors that are expressed in the brain. The mechanisms by which they are normally released are, however, poorly understood. Gene therapy with either galanin [17] or neuropeptide $Y$ [18] have shown promising effects. Because Neuropeptide $Y$ (NPY) acts on both proexcitatory $\mathrm{Y} 1$ and proinhibitory $\mathrm{Y} 2$ receptors, combined gene therapy using NPY and Y2 has been proposed as suitable for clinical translation [19].

(ii) Potassium channel overexpression. Potassium channels represent a very large family of genes, most of which encode proteins that have to assemble as tetramers. They differ with respect to their neuron-type and neuron compartment (dendrites vs. axons) expression and to their biophysical properties (voltage dependence, activation and inactivation kinetics). Overexpression of the Shakertype potassium channel Kv1.1 has been shown to be effective in both preventing epileptogenesis and suppressing seizures [20]. Overexpression of the channel leads to a moderate decrease in both neuronal excitability and neurotransmitter release from axon terminals [21].

(iii) Chemogenetics. Gene therapy, in common with surgery and cell therapy, is irreversible in that introduction of genes into the brain cannot easily be undone. Although preclinical studies have generally shown that antiepileptic gene therapy restricted to a small area of the brain is well tolerated, it is difficult to extrapolate from the rodent brain to the human brain, especially if it is necessary to target a 
large epileptogenic zone that overlaps with eloquent cortex. Chemogenetics refers to using gene transfer to express a receptor that is insensitive to endogenous neurotransmitters but is sensitive to exogenous drugs that can be given on demand. Promising results have been obtained using an inhibitory Designer Receptor Exclusively Activated by a Designer Drug (DREADD) derived from the human M4 muscarinic receptor, hM4D (Gi) [22]. This inhibitory G protein-coupled receptor is insensitive to acetylcholine but sensitive to a number of compounds including some atypical antipsychotic drugs that could, in principle, be repurposed for use as part of a receptor-drug therapeutic combination. Ondemand suppression of seizures using hM4D (Gi) has been demonstrated in a rodent model [23]. This approach allows a more refined gene therapy than irreversible and permanent gene transfer of potassium channels or neuropeptides, because the dosage of the activating drug can be adjusted to find an optimum that minimizes interference with normal brain function while suppressing seizures. It could also be administered on demand in the event of clusters of seizures or status epilepticus.

(iv) A further refinement of chemogenetics consists of using a receptor that detects pathological elevations of the endogenous neurotransmitter glutamate and inhibits neurons. This dispenses with the need to give a drug. Successful attenuation of seizures was achieved with a glutamate-gated chloride channel derived from the nematode Caenorhabditis elegans [24]. The glutamate sensitivity of the channel was increased by mutating an amino acid, to allow it to detect extracellular glutamate concentrations in the low micromolar range, consistent with evidence that glutamate is pathologically elevated in human epilepsy. Although this strategy is attractive, because it removes the need to use a drug together with the gene therapy, the use of a nonmammalian receptor calls for further work to determine whether there is a risk of immunogenicity.

In summary, gene therapy is a promising approach to treat refractory epilepsy, which builds on fundamental knowledge of seizure mechanisms.

\section{Stem cell therapy}

Persistence of seizures in acquired epilepsies is associated with substantial loss of inhibitory GABAergic interneurons and their axon terminals. Such observations have led to the hypothesis that grafting of new GABAergic interneurons into epileptic foci would enhance the inhibitory synaptic neurotransmission and suppress the occurrence of spontaneous seizures. Indeed, various investigations in diverse animal models of epilepsy have reported that grafting of GABAergic precursor cells derived from fetal brain into epileptic regions can reduce seizures [25]. Notably, the precursor cells derived from the medial ganglionic eminence (MGE) of the embryonic brain provided maximal efficacy for suppressing seizures [25-29]. Currently, MGE cells are considered the most appropriate donor cell types for treating epilepsy as these cells exhibit pervasive migration, differentiate into multiple subclasses of GABAergic interneurons, get incorporated into the hippocampal circuitry, enhance inhibitory neurotransmission in the hippocampus, and significantly suppress the occurrence of spontaneous seizures. 
Grafting of human MGE (hMGE)-like GABAergic progenitors generated from embryonic stem cells has also been found to be effective in suppressing seizures and reversing seizure-related comorbidities in a mouse model of epilepsy [30]. The hMGE graft-derived GABAergic interneurons have also been shown to increase inhibitory synaptic transmission in the epileptic hippocampus through an apt integration with the host neural circuitry. Even so, MGE cell therapy has not progressed to clinical investigation because the use of human fetal MGE cells is impractical, owing to ethical issues and the difficulty in acquiring the required aggregate of human fetal MGE tissues. Though the availability of hMGE cells derived from human embryonic stem cells has relatively attenuated ethical concerns, their use does not allow patient-specific cell therapy. Because such treatments require immune suppression for prolonged periods after grafting, unpleasant side effects and slow graft rejection may occur over time. An approach of patient-specific cell therapy using humaninduced pluripotent stem cells (hiPSCs) would likely alleviate the need for long-term immune suppression after grafting as well as improve the long-term survival and integration of grafts. Therefore, the hMGE progenitors derived from hiPSCs appear to be the most suitable donor cell types for grafting in epilepsy, as the use of such cells is not associated with ethical issues and is also compatible with a patient-specific cell therapy, particularly for nongenetic epilepsies.

Recently, human MGE-like (hMGE) cells generated from hiPSCs through a directed differentiation method were grafted into the hippocampi of rats that underwent status epilepticus [31]. Such grafting resulted in significantly diminished frequency and intensity of spontaneous seizures as well as reduced Electroencephalography (EEG) power in interictal periods. The grafted hiPSC-hMGE cells displayed robust long-term survival, pervasive migration to various hippocampal subfields and differentiated mostly into GABAergic interneurons expressing different calcium-binding proteins (parvalbumin and calretinin) and neuropeptides (neuropeptide $Y$ and somatostatin). The axons from graft-derived interneurons made synaptic contacts on the soma and dendrites of the host dentate granule cells and Ammon's horn (CA1) pyramidal neurons. The study also showed that graftderived interneurons were directly involved in the suppression of spontaneous seizures. This phenomenon was evident from an increased seizure activity when graft-derived interneurons were silenced in an experiment using donor hiPSC-hMGE cells transduced with AAV5 vector carrying hSyn-hM4Di-mCherry DREADDs. Grafting of hMGE cells also maintained higher levels of normal neurogenesis, with reductions in abnormal neurogenesis, loss of host interneurons, and aberrant mossy fiber sprouting [31]. Moreover, epileptic animals receiving hMGE cell grafts displayed improved cognitive function and reduced depressive-like behavior. These improved outcomes may be related to reduced seizures, maintenance of normal neurogenesis at higher levels, and reduced abnormal neurogenesis mediated by hMGE cell grafts because both persistent seizures and impaired neurogenesis in chronic epileptic conditions contribute to cognitive and mood dysfunction [32-34].

Thus, hiPSC-MGE cell therapy approach has the potential for developing patient-specific cell therapy for nongenetic epileptic conditions such as TLE. However, clinical trials using hiPSC-derived cells have been limited so far because of the perceived safety issues. Some of these include propensity of induced pluripotent stem cells (iPSCs) for exhibiting epigenetic alterations and genomic instability [35] and the concern that the presence of even a few pluripotent stem cells in the graft cell suspension may cause teratoma or undesired differentiation into a broad range of somatic cells, if they exhibit incessant proliferation after 
transplantation. In the study by Upadhya and colleagues, minor fractions of graft-derived cells displayed proliferative activity and expressed markers of neural progenitor cells at $\sim 5$ months after grafting, but none of the graft-derived cells expressed pluripotent stem cell markers [31]. Nonetheless, for clinical translation, it would be necessary to make sure that postmitotic MGE cells displaying genomic stability are employed. Future studies will, therefore, need to investigate the efficacy of purified hiPSC-derived MGE cells that have been screened for genomic stability and also partially differentiated into GABAergic interneurons at the time of grafting. Additionally, before the transition into the clinic setting, the appropriate dose of MGE cells required for functional improvements needs to be assessed.

Likewise, for clinical translation, the consequences of hiPSC-MGE cell grafting into the hippocampus in the chronic phase of epilepsy on seizures and on related comorbidities must be evaluated critically. Such studies are vital, as the most suitable candidates for stem cell therapy would be patients presenting drug-resistant epilepsy or those who are considered for hippocampal resection surgery. Patients with pharmacoresistant epilepsy also develop severe comorbidities such as cognitive impairments and depression. Hence, comprehensive studies assessing the survival, integration, and proficiency of grafts placed into the epileptic brain region of animals that have displayed spontaneous seizures for several months and persistent cognitive and mood dysfunction are crucial. Such studies may uncover diminished survival, differentiation, and integration of graft-derived interneurons due to adverse microenvironmental changes in the chronically epileptic brain regions, which may require the application of appropriate graft augmentation strategies [25].

\section{Traditional and novel antiepileptic devices}

Neurostimulation techniques deliver electrical or magnetic currents to modulate neuronal activity to achieve seizure suppression using invasive and noninvasive modalities.

Vagal nerve stimulation (VNS) is a European community (CE)marked and Food and Drug Administration (FDA)-approved adjunctive treatment for patients with refractory epilepsy that is routinely available in many epilepsy centers and used in more than 100,000 patients worldwide. It comprises a programmable pulse generator implanted in the subclavicular region and a bipolar lead that connects the generator to the left vagal nerve in the neck. Typical stimulation parameters are the following: $\mathrm{N}$ 1.5-2.0 mA output current (range: 0-3.5 $\mathrm{mA}), 250-500 \mu \mathrm{s}$ pulse width $(130-1000 \mu \mathrm{s})$, and $20-30 \mathrm{~Hz}$ signal frequency $(1-30 \mathrm{~Hz})$ delivered with a $30 \mathrm{~s}$ ON (7-60 s)/5 min OFF (0.2-180 min) duty cycle [36]. The mechanism of action is incompletely understood but involves - among others - afferent vagal nerve fibers modulating the activity of brainstem nuclei such as the nucleus of the solitary tract (the predominant afferent target) and its multitude of downstream projections including the locus coeruleus and the raphe nucleus with widespread noradrenergic and serotonergic projections in the brain. The efficacy of VNS was demonstrated in two large randomized controlled trials showing a $50 \%$ or more reduction in seizure frequency in $31 \%$ (lowstimulation $13 \%, p=0.02$ ) and $23.4 \%$ (low-stimulation $15.7 \%, p$ N 0.05 ) of patients (VNS randomized clinical trials (RCT) 1 and 2). Forty-four percent of patients showed $a \geq 50 \%$ seizure reduction after 2 and 3 years of open-label extended follow-up. Other open-label and uncontrolled trials have confirmed $\geq 50 \%$ seizure reductions in 50 to $64 \%$ of patients after a 
mean follow-up of 3 to 59 months. Seizure freedom at long-term follow-up is observed in less than $10 \%$ of patients. Side effects are typically mild and tend to improve over time. These include hoarseness, throat paresthesia or pain, coughing, and dyspnea occurring during the stimulation ON periods and almost always resolve with adjustment of parameter settings. A few intraoperative cases of severe bradycardia and/or asystole have been described. Sudden unexpected death in epilepsy (SUDEP) rate is lower in VNS-treated patients [37,38]. A novel feature of the newest VNS models is the ability to detect ictal tachycardia and then automatically deliver additional stimulation to abort the seizure or reduce seizure duration and/or severity and long-term seizure frequency $[39,40]$.

Cortical and deep brain stimulations are invasive intracranial neurostimulation techniques that have been investigated as a treatment option for patients with refractory epilepsy since more than 40 years. Following positive results in two large randomized controlled clinical trials, FDA approval has been granted to both responsive stimulation of the ictal onset zone (RNS) (2013) and anterior thalamic deep brain stimulation (2018) as a treatment for patients with medically refractory focal epilepsy (Sante trial and Neuropace trial) $[41,42]$. In the blinded phase of the Sante trial, a $29 \%$ greater seizure reduction was found in the active versus the control group. Responder rates by 2 and 6 years were $54 \%$ and $68 \%$ respectively. In the RNS trial, there was a $20 \%$ greater seizure reduction in the 12 -week blinded phase, and median seizure frequency reductions were between $48 \%$ and $66 \%$ over 3 to 6 years postimplantation $[43,44]$. The most relevant reported side effects were depressive mood and memory impairment, besides local side effect of the implantation. The best seizure outcome has been obtained in patients in whom 2 or more of 4 contacts were effectively placed in the anterior nucleus of the thalamus [45].

After promising results in a pilot trial, a larger RCT $(n=50)$ was initiated by De Giorgio to evaluate the efficacy, tolerability, and safety of noninvasive transcutaneous bilateral stimulation of the supraorbital branches of the trigeminal nerve (TNS) [46]. The 50\% responder rate $(30.2$ versus $21.1 \%, p=0.31)$ and percentage seizure frequency reduction (16.1 versus $-10.5 \%, p=0.51$ ) were not statistically significantly different between the high (assumed therapeutic) and the low (assumed subtherapeutic) stimulation group over the entire 18-week stimulation period (primary outcome measure). Subgroup analysis did show increasing efficacy over time with a significant number of $50 \%$ responders after 18 weeks in the high-stimulation group only ( 40.5 versus $15.6 \%$ ). Adverse events were mild: anxiety $(4 \%)$, headache (4\%), and skin irritation (14\%). Open-label extended follow-up studies reported inconclusive results.

Transcranial direct current stimulation (tDCS) does not induce action potentials but may modulate neuronal excitability by changing the resting membrane potential by constant transcranial delivery of weak currents $(1-2 \mathrm{~mA})$ via two electrodes. Cathodal tDCS is hypothesized to suppress seizures by inducing membrane hyperpolarization and has been investigated in six RCTs. Three studies evaluated the effect of a single 20 -minute session of cathodal tDCS. While 2 studies found a significant reduction in the number of interictal epileptiform discharges in patients with malformations of cortical development and in children with focal epilepsy, only Assenza and colleagues found a statistically significant and clinically relevant $71 \%$ reduction in seizure frequency compared with sham stimulation $(+25 \%)$ in patients with TLE in the week following tDCS [47-49]. Three studies evaluated the effect of 3 to 5 sessions of cathodal tDCS. One study reported a significant $99.8 \%$ reduction 
in seizure frequency in 22 patients with Lennox-Gastaut syndrome on the fifth day of tDCS applied over the primary motor cortex. After 4 weeks, seizure frequency was still significantly lower in the tDCS (56.0\% reduction) compared with the sham group. Additionally, a significant reduction in interictal epileptiform discharges was demonstrated. The other 2 studies evaluated the effects of tDCS in refractory TLE. San-Juan and colleagues reported significant reduction in seizure frequency following $3(-43.4 \%)$ and $5(-54.6 \%)$ sessions of tDCS compared with placebo after two months (not after one month). Differences in $50 \%$ responder rate did not achieve statistical significance. Others performed a crossover study with 12 patients and showed a significant $-84.2 \%$ reduction in seizure frequency compared with baseline in the sinusoidal tDCS group but not in the sham group $(-12.6 \%)$. However, they did not directly compare both groups. This was also the case for the $50 \%$ responder rate, with $83.3 \%$ and $16.7 \% 50 \%$ responders in the tDCS and sham group, respectively. Half of the patients were even seizure-free in the month following active tDCS. Reported adverse events are rather mild and include tingling sensations, mild itch, moderate headache, and the occurrence of skin burn under the reference electrode $[47,49]$.

Transcranial magnetic stimulation uses magnetic fields to stimulate nerve cells in the brain as deep as $2 \mathrm{~cm}$. Low-frequency repetitive Transcranial magnetic stimulation (TMS) has been shown to induce long-lasting reductions in cortical excitability and, consequently, has been proposed as a treatment for epilepsy. Eight RCTs ( $n=11$ to 64$)$ have evaluated the efficacy of 5 to 10 days low-frequency $(0.33-1 \mathrm{~Hz})$ Repetitive transcranial magnetic Stimulation (rTMS) in patients with refractory focal epilepsy. In most of these studies, the epileptogenic focus was targeted (vertex in case of multifocal or nonlocalizable), but in 2 trials, the vertex was the target independent of the localization of the epileptogenic region. Five studies compared active (assumed therapeutic) with sham stimulation, one compared two stimulation intensities ( 20 and $90 \%$ of resting motor threshold), and one evaluated 2 different stimulation parameters differing in the number of pulses per session (1500 versus 3000 pulses). Only three trials could demonstrate a significant reduction in seizure frequency compared with baseline. One study showed a significantly lower seizure frequency after two weeks of high-stimulation rTMS (8.9 to 1.8 seizures per week) but not low-stimulation rTMS ( 8.6 to 8.4 seizures per week), corresponding to a significant $80.6 \%$ greater reduction in seizure frequency with the first group. Another study found a significant $72 \%$ reduction in seizure frequency in the active rTMS group compared with baseline. This was not found in the control group, but an active comparison between both groups was not reported. In the study of Tergau and colleagues, actively treated patients experienced a significant approximately $40 \%$ reduction in seizure frequency compared with baseline, but this difference was not significant when compared with the placebo group. Reported adverse events include headache, dizziness, and tinnitus, but in none of the RCTs, these occurred at statistically significantly higher rates in the active treatment group [50-52]. In conclusion, although there is some evidence that rTMS is safe and well-tolerated; there is insufficient evidence that proves its efficacy in reducing seizure frequency in patients with refractory epilepsy. Unresolved questions remain with regard to patient selection, the optimal stimulation protocol (parameters and target), the duration of the putative treatment effect, and how to adequately blind participants.

Transcutaneous VNS (tVNS) was developed as a noninvasive alternative to vagus nerve stimulation and stimulates the auricular branch of the vagus nerve. Two uncontrolled openlabel trials demonstrated $50-55 \%$ reductions in seizure frequency, with similar numbers of 
patients experiencing a $\geq 50 \%$ reduction in seizure frequency. Results in 3 randomized controlled trials were mixed. Bauer and colleagues $(n=76)$ found no significant difference between $1-\mathrm{Hz}$ (assumed subtherapeutic) and $25-\mathrm{Hz}$ (assumed therapeutic) stimulation groups in terms of seizure frequency reduction or $50 \%$ responder rates, although seizure frequency was $-34.2 \%$ lower compared with baseline only in the $25-\mathrm{Hz}$ group [53]. A study with 47 patients found a statistically significant lower monthly seizure frequency after 12 months of stimulation in the treatment group (assumed therapeutic stimulation of Ramsay Hunt zone) compared with the control group (stimulation of earlobe) and to baseline (around $40 \%$ decrease) [54]. Another study $(n=144)$ demonstrated a statistically significant treatment effect between transcutaneous auricular vagus and nonvagus nerve stimulation in terms of seizure frequency $(-42.6$ versus $-11.5 \%)$ and $50 \%$ responder rates $(41.0$ versus $27.5 \%$ ) [55]. Side effects of transcutaneous VNS include local skin irritation and headache. More, large, and welldesigned RCTs are needed to confirm these promising results.

\section{Precision medicine}

The U.S. National Research Council defines precision medicine as 'the tailoring of medical treatment to the individual characteristics of each patient', specifying that 'it does not literally mean the creation of drugs or medical devices that are unique to a patient, but rather the ability to classify individuals into subpopulations that differ in their susceptibility to a particular disease, in the biology and/or prognosis of those diseases they may develop, or in their response to a specific treatment. Preventive or therapeutic interventions can then be concentrated on those who will benefit, sparing expense and side effects for those who will not' [56]. The term 'precision medicine' is often used interchangeably with the term "personalized medicine", although it has been suggested that 'precision medicine' is a better wording to make it clear that it does not involve application of unique treatments designed for each individual [56].

In a broad sense, a component of precision medicine has been part of epilepsy management for many decades - in fact, AEDs are usually selected after careful consideration of individual characteristics such as seizure types, epilepsy syndrome, comorbidities, comedications, and expected vulnerability to specific adverse effects [57]. However, in recent years, the term 'precision medicine' in epilepsy is increasingly used to describe medical treatments that target specifically the mechanisms responsible for the manifestations of the disease in individual patients [58]. Unlike conventional treatments, precision treatments are delivered rationally based on the identification of the molecular etiology of the epilepsy and elucidation of the underlying functional mechanisms. At the current state of knowledge, most of the advances that have been made in the area of precision medicine for epilepsy stem from the discovery of epilepsy genes and the related discipline of pharmacogenomics [58-61].

The use of the ketogenic diet to treat glucose transporter 1 (GLUT1) deficiency syndrome is probably the best example of precision medicine applied to epilepsy [62]. In patients with GLUT1 deficiency, the uptake of glucose into the brain is impaired because of a solute carrier family 2 member 1 (SLC2A1) gene mutation that impairs the efficiency of the GLUT1 transporter in the blood-brain barrier. The ketogenic diet provides neurons with an alternative source of energy, thereby compensating for the consequences of the metabolic defect [62]. Other examples of precision medicine include the use of phenytoin for the 
treatment of epileptic encephalopathies caused by the sodium voltage-gated channel alpha subunit 8 (SCN8A) mutations resulting in the gain-of-function of the sodium channel Nav 1.6, [63], or the use of everolimus to control treatment-resistant focal seizures associated with tuberous sclerosis complex (TSC) [64]. At least in the case of everolimus for focal epilepsy associated with TSC, efficacy has been clearly demonstrated in a doubleblind parallel-group adjunctive-therapy randomized controlled trial in which exposure to trough everolimus concentrations of 3-7 ng/mL (low exposure, $\mathrm{n}=117$ ) and 9-15 $\mathrm{ng} / \mathrm{mL}$ (high exposure, $\mathrm{n}=$ $130)$ was compared with placebo $(n=119)$ [64]. The proportion of patients with $a \geq 50 \%$ reduction in seizure frequency (compared with baseline) during the 12-week maintenance period was $15.1 \%$ in the placebo group, $28.2 \%$ in the low-exposure group ( $p=0.0077$ ), and $40.0 \%$ in the high-exposure group $(p=0.0001)$.

Another application of precision medicine relates to avoidance of AEDs that cause worsening of seizures by aggravating the underlying molecular defect - for example, sodium channels such as carbamazepine, phenytoin, and lamotrigine are generally best avoided in patients with Dravet syndrome and other epilepsies caused by sodium voltagegated channel alpha subunit 1 (SCN1A) mutations leading to loss of function of Nav $1.1[60,65-67]$. Other examples of genomic-guided precision therapies have been reviewed recently $[59,60,67]$.

In recent years, application of next generation sequencing has accelerated the discovery of new epilepsy genes, with these discoveries often having treatment implications $[60,68]$. Indeed, diagnostic genetic studies in individual patients are increasingly coupled with functional studies at molecular level, which include the screening for compounds that may counteract the functional defect [69]. Not uncommonly, these compounds are often drugs already available in the market for other indications. Not surprisingly, in a publicly accessible database of prescribable drugs with efficacy in experimental epilepsies, the list of appealing candidates for repurposing is highly enriched with drugs that target proteins of known causal human epilepsy genes [70].

Examples of repurposable drugs for which some evidence of potential clinical efficacy is already available include memantine for earlyonset epileptic encephalopathy due to gain-offunction glutamate ionotropic receptor NMDA type subunit 2A (GRIN2A) mutations [71] and quinidine for epilepsies caused by pathogenic variants of genes encoding for potassium channels, particularly potassium sodiumactivated channel subfamily T member 1 (KCNT1) [table]. Gain-offunction KCNT1 pathogenic variants have been found to cause a spectrum of severe focal epilepsies with onset in early infancy, including some cases of West syndrome, of epilepsy of infancy with migrating focal seizures, and of early-onset severe autosomal dominant nocturnal frontal lobe epilepsy [72,73]. In in vitro studies, quinidine has been found to variably reverse the pathogenic gain-of-function of the affected potassium channels $[72,73]$. Clinically, quinidine has been reported to be beneficial in some patients with severe epilepsies caused by gain-of-function mutations of KCNT1 [74-77] and, possibly, potassium sodium-activated channel subfamily T member 2 (KCNT2) [78], although lack of therapeutic benefit and/or cardiac toxicity in individuals with these epilepsies has also been reported [75-82]. Notably, a randomized double-blind trial of quinidine in 6 patients with severe autosomal dominant nocturnal frontal lobe epilepsy (ADNFL) associated with KCNT1 gainof-function mutations failed to show any efficacy, possibly because serious cardiac toxicity occurring at low doses prevented the achievement of potentially 'therapeutic' serum 
quinidine levels [82]. The reason for the conflicting results on the efficacy and safety of quinidine in epilepsies due to KCNT1 mutations is unclear. One possibility is that different pathogenic variants have different sensitivity to quinidine [73]. Age factors may also be important, because it has been suggested that children below 4 years of age are more likely to respond to quinidine than older patients [77] [table]. In any case, these data demonstrate the need for caution in interpreting results of single-case reports and the need for careful preclinical and clinical evaluation of novel precision therapies before such treatments can be considered established.

Overall, available evidence indicates that precision therapies are applicable to an important percentage of individuals with rare as well as common forms of epilepsy $[67,83]$, and drug design and drug development are increasingly being influenced by precisionmedicine approaches [61,83-85].

Although extensive research currently focuses on genome-guided therapies, important opportunities also exist in other areas. As described in the next section, examples include the use of immunosuppressive therapies for autoimmune epilepsies [86] and the research on treatments targeting neuroinflammation in epilepsies where inflammatory mechanisms are likely to play a pathogenic role [87]. In the future, selection of patients for precision therapies is likely to rely to an important extent on the use of biomarkers as indicators of the underlying etiology of the disease, or as predictors of response to specific treatments [88].

\section{Advances in the therapy of epileptic encephalopathies in children}

Here, we discuss the introduction of new AEDs, immunotherapy, and development of precision therapy. There are a number of studies evaluating the efficacy of Adrenocorticotropic hormone (ACTH), hormonal therapy in general (either ACTH or oral steroids), and vigabatrin in West syndrome showing that in patients with nontuberous sclerosis, hormonal therapy is superior to vigabatrin and that ACTH may be more effective than oral steroids. These studies have resulted in the current guidelines of using hormonal therapy first, unless the patient has tuberous sclerosis, and were reviewed elsewhere previously [89-91]. However, other than these studies, there is a lack of controlled studies of the therapy of other epileptic encephalopathies and a need for more investigations in this area [92]. Cannabidiol has recently been approved for the therapy of seizures associated with Dravet syndrome and with Lennox-Gastaut syndrome [93,94]. Fenfluramine promises to be another medication that may be helpful in these syndromes [95]. Many other medications are under study: some involve mechanisms similar to known AEDs like GABA A receptor agonists, some involve novel mechanisms such as stimulation of melatonin receptors, some are repurposed drugs previously used for other indications as described below, and others with yet unknown mechanisms of action [96].

Immunotherapy involves therapy of infantile and childhood epileptic encephalopathies as well as therapy of autoimmune epilepsies caused by autoimmune encephalitis. Hormonal steroid therapy remains the mainstay of therapy for infantile spasms. The addition of vigabatrin to hormonal therapy as initial therapy in cases of new-onset infantile spasms does not appear to improve outcome [97]. In the special situation of TSC, vigabatrin is a drug of first choice for infantile spasms. Current ongoing research (EPISTOP study) is aiming to determine if therapy with vigabatrin started in young infants before onset of seizures can 
prevent the development of later spasms or epilepsy [98]. Steroid therapy is also used for later-onset epileptic encephalopathies. In a series of 147 patients with electrical status epilepticus in sleep (ESES), steroid therapy (oral and or pulse steroids) had better efficacy than other therapies [99]. Pulse steroid therapy with methylprednisolone given on three consecutive days and repeated monthly for 4-6 months is emerging as an alternative to daily steroid administration to avoid side effects of daily steroid therapy [100]. However, controlled prospective studies regarding this alternative are still lacking. Intravenous immunoglobulin (IVIG) has been used for the therapy of Landau- Kleffner syndrome and other intractable epilepsy syndromes and epileptic encephalopathies, but the definitive placebo-controlled studies have not been performed, and thus, a recent Cochrane review concluded that definitive conclusions about its efficacy cannot be made at this stage [101103]. A case report of Landau-Kleffner syndrome associated with a GRIN2A mutation described a patient whose syndrome responded only to steroid and IVIG therapy despite the presumed genetic etiology [104]. Therapy of autoimmune encephalitis currently consists of the following [105]: first-line immunotherapy includes intravenous steroids over 3-5 days (may need to be repeated if needed), IVIG (over 2 days then monthly), and plasmapheresis. However, plasmapheresis is usually only effective at temporarily removing peripheral antibodies. In addition, duration and intervals of intravenous steroids and IVIG vary. For children not showing improvement within 2 weeks, or declining on a first-line therapy, escalating therapy to second-line treatments is recommended. Rituximab and cyclophosphamide are considered second-line agents, although cyclophosphamide is used less commonly in children than in adults. Antibodies to intracellular antigens such as glutamic acid decarboxylase (GAD) encephalitis may benefit from more intense immunotherapy at diagnosis because these antibodies are associated with more destructive inflammatory responses. Hashimoto encephalitis is, in about half the cases, highly responsive to steroids. Intravenous methylprednisolone is used most often, although oral prednisone is also reported from 6 weeks to several years. Intravenous immunoglobulin, rituximab, mycophenolate mofetil, and methotrexate have also been used. Novel antiinflammatory therapies such as anakinra, the human recombinant IL1-Ra receptor antagonist, may prove to be effective based on initial encouraging limited experience [106]. This agent is currently being investigated as a potential immunotherapy of the febrile infection-related epilepsy syndrome (FIRES).

Gene therapy, which is approved for one type of retinopathy and for certain leukemias and lymphomas, has now reached human trials in a number of disorders that can be associated with epilepsy. These include Canavan disease, infantile and late infantile neuronal ceroid lipofuscinosis (NCL), mucopolysaccharidoses (MPS) IIIA and IIIB, Aromatic $L$ amino acid decarboxylase (AADC) deficiency, and metachromatic leukodystrophy. Enzyme replacement is another example of precision therapy and now is available for NCL type II, which is consistently associated with severe epilepsy [107] as well as for other types of lysosomal storage diseases that may be associated with epilepsy including Gaucher disease type I, and MPSI II IVA and VI. Examples of distant downstream "precision" therapy are many and relate to recognition of etiology (usually the type of gene mutation)-related side effect or response to specific AEDs or repurposed drugs. Adverse effects precision-related recommendations include the following: with SCN1A mutations - avoid sodium channel drugs like lamotrigine, with DNA Polymerase Gamma, Catalytic Subunit (POLG) mutations - avoid valproate because of potential hepatotoxicity, with human leukocyte antigen (HLA) $B^{\star}$ 15:02 allele positivity - avoid carbamazepine because of risk of Stevens-Johnson's 
syndrome, and with myoclonic epilepsy - sodium channel drugs can worsen myoclonus. There are also reports of levetiracetam very infrequently aggravating other types of myoclonus, such as juvenile myoclonic epilepsy [108]. More data are available regarding precision therapy-related recommendations since drug repurposing research is currently very active [59]. There are multiple companies, core facilities, and institutes engaged in that (for example, Broad Institute Repurposing Hub https://clue.io/repurposing). Also, there is a database for that for epilepsy, i.e., the Drug repurposing for epilepsy Prescribable Drugs with Efficacy in Experimental Epilepsies (PDE3) database: www. liverpool.ac.uk/D3RE/PDE3 [70]. Table 1 below shows some of the information related to potential etiology-specific drugs in severe pediatric epilepsies. One has to caution that with the exception of everolimus use in TSC-related seizures and cannabidiol in Dravet syndrome, which are FDA-approved, there is much need for more data to further substantiate, or refute, the potential benefits advocated for by case reports, case series, or preclinical data on which such observation is based. 
Table 1

Potentially effective therapies according to type of specific mutations. For a source of references, please refer to recent review articles [59,61,92].

\begin{tabular}{|l|l|}
\hline Type of mutation & Potentially beneficial therapy \\
\hline CHRNA4 & Zonisamide, acetazolamide and nicotine patches \\
\hline GRIN2A & Memantine (not GRIN2B so far) \\
\hline KCNQ2 & Retigabine \\
\hline KCNT1 & Quinidine \\
\hline$P C D H 19$ & Bromide, clobazam \\
\hline PLCB1 & Inositol \\
\hline PRRT2 & Carbamazepine, oxcarbazepine \\
\hline SCN1A (Dravet) & GABAergic drugs, fenfluramine, cannabidiol \\
\hline SCN2A (Early infantile epileptic \\
encephalopathy (EIEE)) & High dose phenytoin, levetiracetam \\
\hline SCN2A (EIEE, status) & Lidocaine, acetazolamide \\
\hline SCN8A & $\begin{array}{l}\text { High dose phenytoin, amitriptyline, nilvadipine, } \\
\text { carvedilol, carbamazepine }\end{array}$ \\
\hline SLC2A1 & Ketogenic diet \\
\hline STXBP1 & Levetiracetam, folinic acid, vigabatrin \\
\hline TSC1 and 2 & $\begin{array}{l}\text { Everolimus (could this also apply to mechanistic target } \\
\text { of rapamycin (mTOR) pathway } \\
\text { somatic-cell-mutations-related focal cortical } \\
\text { dysplasias?) }\end{array}$ \\
\hline
\end{tabular}

CHRNA4 (cholinergic receptor nicotinic alpha 4 subunit); GRIN2A (glutamate ionotropic receptor N-methyl-D-aspartate (NMDA) type subunit 2A); KCNQ2 (potassium voltagegated channel subfamily $\mathrm{Q}$ member 2); KCNT1 (potassium sodium-activated channel subfamily $T$ member 1); PCDH19 (protocadherin 19); PLCB1 (phospholipase C beta 1); PRRT2 (prolinerich transmembrane protein 2); SCN1A (sodium voltage-gated channel alpha subunit 1); SCN2A (sodium voltage-gated channel alpha subunit 2); SCN8A (sodium voltage-gated channel alpha subunit 8); SLC2A1 (solute carrier family 2 member 1); STXBP1 (syntaxinbinding protein 1); TSC1 and 2 (TSC complex subunits 1 and 2). Except for everolimus in TSC-associated focal epilepsy [64] and for cannabidiol $[93,94]$ and fenfluramine ([109] in Dravet syndrome, none of the treatments listed in this table have been validated in controlled trials in patients with the indicated mutations, and for some of these treatments, evidence for efficacy is speculative or controversial. 


\section{Acknowledgments}

This review was presented at the 12th Qatar Epilepsy Symposium in February 2019 by the authors. We thank Hamad Medical Corporation for supporting this event.

\section{Disclosures}

Ali A. Asadi-Pooya, consultant: UCB Pharma; Honorarium: Cobel Daruo; Royalty: Oxford University Press (Book publication).

Emilio Perucca received speaker's or consultancy fees from Axovant, Biogen, Eisai, GW Pharma, Sanofi, Sun Pharma, Takeda, UCB Pharma, and Xenon Pharma, and publication royalties from Wiley and Elsevier.

Paul Boon received speaker's or consultancy fees from UCB, Livanova and Medtronic.

Dimitri M Kullmann holds patents in the field of gene therapy for epilepsy and has acted as a consultant for GSK.

The rest of the authors' declarations of interest: none.

\section{Funding}

This research did not receive any specific grant from funding agencies in the public, commercial, or not-for-profit sectors.

\section{References}

[1] Ryvlin P. The modern challenges of drug resistant epilepsy. Epileptic Disord 2005;7 (Supll. 1):S1-2.

[2] Chen Z, Brodie MJ, Liew D, Kwan P. Treatment outcomes in patients with newly diagnosed epilepsy treated with established and new antiepileptic drugs: a 30-year longitudinal cohort study. JAMA Neurol 2018 Mar 1;75(3):279-86. https://doi. org/10.1001/jamaneurol.2017.3949.

[3] Asadi-Pooya, Rostami C. History of surgery for temporal lobe epilepsy. Epilepsy Behav 2017 May;70(Pt A):57-60. https://doi.org/10.1016/j.yebeh.2017.02.020 Epub 2017 Apr 12.

[4] Tang F, Hartz AMS, Bauer B. Drug-resistant epilepsy: multiple hypotheses, few answers. Front Neurol 2017 Jul 6;8:301. https://doi.org/10.3389/fneur.2017. 00301 eCollection 2017.

[5] Tishler DM, Weinberg KI, Hinton DR, Barbaro N, Annett GM, Raffel C. MDR 1 gene expression in brain of patients with medically intractable epilepsy. Epilepsia 1995 Jan; $36(1): 1-6$.

[6] Feldmann M, Asselin MC, Liu J, Wang S, McMahon A, Anton-Rodriguez J, et al. Pglycoprotein expression and function in patients with temporal lobe epilepsy: a case-control study. Lancet Neurol 2013 Aug;12(8):777-85.

[7] Volk HA, Burkhardt K, Potschka H, Chen J, Becker A, Loscher W. Neuronal expression of the drug efflux transporter P-glycoprotein in the rat hippocampus after limbic seizures. Neuroscience 2004;123(3):751-9.

[8] Ma A, Wang C, Chen Y, Yuan W. P-glycoprotein alters blood-brain barrier penetration of antiepileptic drugs in rats with medically intractable epilepsy. Drug Des Devel Ther 2013 Dec 3;7:1447-54. https://doi.org/10.2147/DDDT.S52533 eCollection 2013. 
[9] Asadi-Pooya AA, Sperling MR. Potentiation of anti-epileptic drugs effectiveness by pyronaridine in refractory epilepsy. Med Hypotheses 2007;69(3):560-3 Epub 2007 Mar 26.

[10] Asadi-Pooya AA, Razavizadegan SM, Abdi-Ardekani A, Sperling MR. Adjunctive use of verapamil in patients with refractory temporal lobe epilepsy : a pilot study. Epilepsy Behav 2013 Oct;29(1):150-4. https://doi.org/10.1016/j.yebeh.2013.07.006 Epub 2013 Aug 22.

[11] Stępień KM, Tomaszewski M, Tomaszewska J, Czuczwar SJ. The multidrug transporter P-glycoprotein in pharmacoresistance to antiepileptic drugs. Pharmacol Rep 2012;64(5):1011-9.

[12] Loscher W. How to explain multidrug resistance in epilepsy? Epilepsy Curr 2005 MayJun;5(3):107-12.

[13] Kullmann DM, Schorge S, Walker MC, Wykes RC. Gene therapy in epilepsy-is it time for clinical trials? Nat Rev Neurol 2014 May;10(5):300-4. https://doi.org/10. 1038/nrneurol.2014.43 Epub 2014 Mar 18.

[14] Deverman BE, Pravdo PL, Simpson BP, Kumar SR, Chan KY, Banerjee A, et al. Credependent selection yields AAV variants for widespread gene transfer to the adult brain. Nat Biotechnol 2016 Feb;34(2):204-9. https://doi.org/10.1038/nbt. 3440 Epub 2016 Feb 1.

[15] Yáñez-Muñoz RJ, Balaggan KS, MacNeil A, Howe SJ, Schmidt M, Smith AJ, et al. Effective gene therapy with nonintegrating lentiviral vectors. Nat Med 2006 Mar; 12(3):34853 Epub 2006 Feb 19.

[16] Dimidschstein J, Chen Q, Tremblay R, Rogers SL, Saldi GA, Guo L, et al. A viral strategy for targeting and manipulating interneurons across vertebrate species. Nat Neurosci 2016 Dec;19(12):1743-9. https://doi.org/10.1038/nn.4430 Epub 2016 Oct 31.

[17] Haberman RP, Samulski RJ, McCown TJ. Attenuation of seizures and neuronal death by adeno-associated virus vector galanin expression and secretion. Nat Med 2003 Aug;9(8):1076-80 Epub 2003 Jul 13.

[18] Richichi C, Lin EJ, Stefanin D, Colella D, Ravizza T, Grignaschi G, et al. Anticonvulsant and antiepileptogenic effects mediated by adeno-associated virus vector neuropeptide $Y$ expression in the rat hippocampus. J Neurosci 2004 Mar 24;24(12):3051-9.

[19] Woldbye DP, Angehagen M, Gøtzsche CR, Elbrønd-Bek H, Sørensen AT, Christiansen $\mathrm{SH}$, et al. Adeno-associated viral vector-induced overexpression of neuropeptide $\mathrm{Y}$ Y2 receptors in the hippocampus suppresses seizures. Brain 2010 Sep;133(9): 2778-88. https://doi.org/10.1093/brain/awq219 Epub 2010 Aug 5.

[20] Wykes RC, Heeroma JH, Mantoan L, Zheng K, MacDonald DC, Deisseroth K, et al. Optogenetic and potassium channel gene therapy in a rodent model of focal neocortical epilepsy. Sci Transl Med 2012 Nov 21;4(161):161 ra152. https://doi. org/10.1126/scitranslmed.3004190 Epub 2012 Nov 12.

[21] Heeroma JH, Henneberger C, Rajakulendran S, Hanna MG, Schorge S, Kullmann DM. Episodic ataxia type 1 mutations differentially affect neuronal excitability and transmitter release. Dis Model Mech 2009 Nov-Dec;2(11-12):612-9. https:// doi.org/10.1242/dmm.003582 Epub 2009 Sep 24. 
[22] Armbruster BN, Li X, Pausch MH, Herlitze S, Roth BL. Evolving the lock to fit the key to create a family of $G$ protein-coupled receptors potently activated by an inert ligand. Proc Natl Acad Sci U S A 2007 Mar 20;104(12):5163-8 Epub 2007 Mar 2.

[23] Kätzel D, Nicholson E, Schorge S, Walker MC, Kullmann DM. Chemical-genetic attenuation of focal neocortical seizures. Nat Commun 2014 May 27;5:3847. https://doi.org/10.1038/ncomms4847.

[24] Lieb A, Qiu Y, Dixon CL, Heller JP, Walker MC, Schorge S, et al. Biochemical autoregulatory gene therapy for focal epilepsy. Nat Med 2018 Sep;24(9):1324-9. https://doi.org/10.1038/s41591-018-0103-x Epub 2018 Jul 9.

[25] Shetty AK, Upadhya D. GABA-ergic cell therapy for epilepsy: advances, limitations and challenges. Neurosci Biobehav Rev 2016 Mar;62:35-47. https://doi.org/10. 1016/j.neubiorev.2015.12.014 Epub 2015 Dec 31.

[26] Waldau B, Hattiangady B, Kuruba R, Shetty AK. Medial ganglionic eminence-derived neural stem cell grafts ease spontaneous seizures and restore GDNF expression in a rat model of chronic temporal lobe epilepsy. Stem Cells 2010 Jul;28(7):1153-64. https://doi.org/10.1002/stem.446.

[27] Hunt RF, Girskis KM, Rubenstein JL, Alvarez-Buylla A, Baraban SC. GABA progenitors grafted into the adult epileptic brain control seizures and abnormal behavior. Nat Neurosci 2013 Jun;16(6):692-7. https://doi.org/10.1038/nn.3392 Epub 2013 May 5.

[28] Henderson KW, Gupta J, Tagliatela S, Litvina E, Zheng X, Van Zandt MA, et al. Longterm seizure suppression and optogenetic analyses of synaptic connectivity in epileptic mice with hippocampal grafts of GABAergic interneurons. J Neurosci 2014 Oct 1;34(40):13492-504. https://doi.org/10.1523/JNEUROSCI.0005-14.2014.

[29] Casalia ML, Howard MA, Baraban SC. Persistent seizure control in epileptic mice transplanted with gamma-aminobutyric acid progenitors. Ann Neurol 2017 Oct; 82(4):53042. https://doi.org/10.1002/ana.25021 Epub 2017 Oct 4.

[30] Cunningham M, Cho JH, Leung A, Savvidis G, Ahn S, Moon M, et al. hPSC-derived maturing GABAergic interneurons ameliorate seizures and abnormal behavior in epileptic mice. Cell Stem Cell 2014 Nov 6;15(5):559-73. https://doi.org/10.1016/ j.stem.2014.10.006 Epub 2014 Nov 6.

[31] Upadhya D, Hattiangady B, Castro OW, Shuai B, Kodali M, Attaluri S, et al. Human induced pluripotent stem cell-derived MGE cell grafting after status epilepticus attenuates chronic epilepsy and comorbidities via synaptic integration. Proc Natl Acad Sci U S A 2019 Jan 2;116(1):287-96. https://doi.org/10.1073/pnas. 1814185115 Epub 2018 Dec 17.

[32] Hattiangady B, Rao MS, Shetty AK. Chronic temporal lobe epilepsy is associated with severely declined dentate neurogenesis in the adult hippocampus. Neurobiol Dis 2004 Dec;17(3):473-90.

[33] Kanner AM. Psychiatric comorbidities in epilepsy: should they be considered in the classification of epileptic disorders? Epilepsy Behav 2016 Nov;64(Pt B):306-8. https://doi.org/10.1016/j.yebeh.2016.06.040 Epub 2016 Nov 21.

[34] Stewart E, Catroppa C, Lah S. Theory of mind in patients with epilepsy: a systematic review and meta-analysis. Neuropsychol Rev 2016 Mar;26(1):3-24. https://doi. org/10.1007/s11065-015-9313-x Epub 2016 Jan 21. 
[35] Yoshihara M, Hayashizaki Y, Murakawa Y. Genomic instability of iPSCs: challenges towards their clinical applications. Stem Cell Rev 2017 Feb;13(1):7-16. https://doi. org/10.1007/s12015-016-9680-6.

[36] Mertens A, Raedt R, Gadeyne S, Carrette E, Boon P, Vonck K. Recent advances in devices for vagus nerve stimulation. Expert Rev Med Devices 2018 Aug;15(8): 527-39. https://doi.org/10.1080/17434440.2018.1507732.

[37] Orosz I, McCormick D, Zamponi N, Varadkar S, Feucht M, Parain D, et al. Vagus nerve stimulation for drug-resistant epilepsy: a European long-term study up to 24 months in 347 children. Epilepsia 2014;55(10):1576-84. https://doi.org/10.1111/epi.12762 Epub 2014 Sep 17.

[38] Boon P, De Cock E, Mertens A, Trinka E. Neurostimulation for drug-resistant epilepsy: a systematic review of clinical evidence for efficacy, safety, contraindications and predictors for response. Curr Opin Neurol 2018 Apr;31(2):198-210. https://doi.org/10.1097/WCO.0000000000000534.

[39] Boon P, Vonck K, van Rijckevorsel K, El Tahry R, Elger CE, Mullatti N, et al. Prospective, multicenter study of cardiac-based seizure detection to activate vagus nerve stimulation. Seizure 2015 Nov;32:52-61. https://doi.org/10.1016/j.seizure.2015.08.011 Epub 2015 Sep 21.

[40] Vonck K, Boon P. Epilepsy: closing the loop for patients with epilepsy. Nat Rev Neurol 2015 May;11(5):252-4. https://doi.org/10.1038/nrneurol.2015.56 Epub 2015 Apr 14.

[41] Fisher R, Salanova V, Witt T, Worth R, Henry T, Gross R, et al, SANTE Study Group. Electrical stimulation of the anterior nucleus of thalamus for treatment of refractory epilepsy. Epilepsia 2010 May;51(5):899-908. https://doi.org/10.1111/j.15281167.2010.02536.x Epub 2010 Mar 17.

[42] Morrell MJ, RNS System in Epilepsy Study Group. Responsive cortical stimulation for the treatment of medically intractable partial epilepsy. Neurology 2011 Sep 27;77(13):1295304. https://doi.org/10.1212/WNL.0b013e3182302056 Epub 2011 Sep 14.

[43] Salanova V, Witt T, Worth R, Henry TR, Gross RE, Nazzaro JM, et al, SANTE Study Group. Long-term efficacy and safety of thalamic stimulation for drug-resistant partial epilepsy. Neurology 2015 Mar 10;84(10):1017-25. https://doi.org/10. 1212/WNL.0000000000001334 Epub 2015 Feb 6.

[44] Bergey GK, Morrell MJ, Mizrahi EM, Goldman A, King-Stephens D, Nair D, et al. Longterm treatment with responsive brain stimulation in adults with refractory partial seizures. Neurology 2015 Feb 24;84(8):810-7. https://doi.org/10.1212/ WNL.0000000000001280 Epub 2015 Jan 23.

[45] Lehtimäki K, Coenen VA, Gonçalves Ferreira A, Boon P, Elger C, Taylor RS, et al. The surgical approach to the anterior nucleus of thalamus in patients with refractory epilepsy: experience from the international multicenter registry (MORE). Neurosurgery 2019 Jan 1;84(1):141-50. https://doi.org/10.1093/neuros/nyy023.

[46] DeGiorgio CM, Soss J, Cook IA, Markovic D, Gornbein J, Murray D, et al. Randomized controlled trial of trigeminal nerve stimulation for drug-resistant epilepsy. Neurology 2013 Feb 26;80(9):786-91. https://doi.org/10.1212/WNL. 0b013e318285c11a. 
[47] San-Juan D, Morales-Quezada L, Orozco Garduño AJ, Alonso-Vanegas M, GonzálezAragón MF, Espinoza López DA, et al. Transcranial direct current stimulation in epilepsy. Brain Stimul 2015;8:455-64.

[48] Assenza G, Campana C, Assenza F, Pellegrino G, Di Pino G, Fabrizio E, et al. Cathodal transcranial direct current stimulation reduces seizure frequency in adults with drug-resistant temporal lobe epilepsy: a sham controlled study. Brain Stimul 2017 Mar-Apr;10(2):3335 Epub 2016 Dec 14.

[49] Regner GG, Pereira P, Leffa DT, de Oliveira C, Vercelino R, Fregni F, et al. Preclinical to clinical translation of studies of transcranial direct-current stimulation in the treatment of epilepsy: a systematic review. Front Neurosci 2018 Mar 22;12:189. https://doi.org/10.3389/fnins.2018.00189 eCollection 2018.

[50] Tergau F, Neumann D, Rosenow F, Nitsche MA, Paulus W, Steinhoff B. Can epilepsies be improved by repetitive transcranial magnetic stimulation? -interim analysis of a controlled study. Suppl Clin Neurophysiol 2003;56: 400-5.

[51] Carrette S, Boon P, Dekeyser C, Klooster DC, Carrette E, Meurs A, et al. Repetitive transcranial magnetic stimulation for the treatment of refractory epilepsy. Expert Rev Neurother 2016;16(9):1093-110. https://doi.org/10.1080/14737175.2016. 1197119 Epub 2016 Jun 30.

[52] Pereira LS, Müller VT, da Mota Gomes M, Rotenberg A, Fregni F. Safety of repetitive transcranial magnetic stimulation in patients with epilepsy: a systematic review. Epilepsy Behav 2016 Apr;57(Pt A):167-76. https://doi.org/10.1016/j.yebeh.2016.01.015 Epub 2016 Mar 10.

[53] Bauer S, Baier H, Baumgartner C, Bohlmann K, Fauser S, Graf W, et al. Transcutaneous vagus nerve stimulation (tVNS) for treatment of drug-resistant epilepsy: a randomized, double-blind clinical trial (cMPsE02). Brain Stimul 2016 May-Jun;9(3):356-63. https://doi.org/10.1016/j.brs.2015.11.003 Epub 2016 Jan 20.

[54] Aihua L, Lu S, Liping L, Xiuru W, Hua L, Yuping W. A controlled trial of transcutaneous vagus nerve stimulation for the treatment of pharmacoresistant epilepsy. Epilepsy Behav 2014 Oct;39:105-10. https://doi.org/10.1016/j.yebeh.2014.08.005 Epub 2014 Sep 18.

[55] Rong P, Liu A, Zhang J, Wang Y, He W, Yang A, et al. Transcutaneous vagus nerve stimulation for refractory epilepsy: a randomized controlled trial. Clin Sci (Lond) 2014 Apr 1. https://doi.org/10.1042/CS20130518 [Epub ahead of print].

[56] National Research Council, Committee on a Framework for Development a New Taxonomy of Disease. Toward precision medicine: building a knowledge network for biomedical research and a new taxonomy of disease. Washington DC: The National Academies Prsshttps://www.plengegen.com/wp-content/ uploads/4_Toward-PrecisionMedicine.pdf; 2011, Accessed date: 12 August 2018.

[57] Moshé SL, Perucca E, Ryvlin P, Tomson T. Epilepsy: new advances. Lancet 2015 Mar 7;385(9971):884-98. https://doi.org/10.1016/S0140-6736(14)60456-6 Epub 2014 Sep 24.

[58] Reif PS, Tsai MH, Helbig I, Rosenow F, Klein KM. Precision medicine in genetic epilepsies: break of dawn? Expert Rev Neurother 2017 Apr;17(4):381-92. https://doi.org/10.1080/14737175.2017.1253476 Epub 2016 Nov 10. 
[59] Poduri A. When should genetic testing be performed in epilepsy patients? Epilepsy Curr 2017 Jan-Feb;17(1):16-22. https://doi.org/10.5698/1535-7511-17.1.16.

[60] Franco V, Perucca E. The pharmacogenomics of epilepsy. Expert Rev Neurother 2015 Oct;15(10):1161-70. https://doi.org/10.1586/14737175.2015.1083424 Epub 2015 Sep 1.

[61] Perucca P, Perucca E. Identifying mutations in epilepsy genes: impact on treatment selection. Epilepsy Res 2019 May;152:18-30. https://doi.org/10.1016/j.eplepsyres. 2019.03.001 Epub 2019 Mar 4.

[62] Koch H, Weber YG. The glucose transporter type 1 (Glut1) syndromes. Epilepsy Behav 2019 Feb;91:90-3. https://doi.org/10.1016/j.yebeh.2018.06.010 Epub 2018 Jul 31.

[63] Boerma RS, Braun KP, van den Broek MP, van Berkestijn FM, Swinkels ME, Hagebeuk EO, et al. Remarkable phenytoin sensitivity in 4 children with SCN8Arelated epilepsy: a molecular neuropharmacological approach. Neurotherapeutics 2016;13:192-7.

[64] French JA, Lawson JA, Yapici Z, Ikeda H, Polster T, Nabbout R, et al. Adjunctive everolimus therapy for treatment-resistant focal-onset seizures associated with tuberous sclerosis (EXIST-3): a phase 3, randomised, double-blind, placebocontrolled study. Lancet 2016 Oct 29;388(10056):2153-63. https://doi.org/10. 1016/S0140-6736(16)31419-2 Epub 2016 Sep 6.

[65] Guerrini R, Dravet C, Genton P, Belmonte A, Kaminska A, Dulac O. Lamotrigine and seizure aggravation in severe myoclonic epilepsy. Epilepsia 1998 May;39(5): 508-12.

[66] Liao WP, Shi YW, Long YS, Zeng Y, Li T, Yu MJ, et al. Partial epilepsy with antecedent febrile seizures and seizure aggravation by antiepileptic drugs: associated with loss of function of $\mathrm{Na}(\mathrm{v})$ 1.1. Epilepsia $2010 \mathrm{Sep} ; 51$ (9):1669-78. https://doi.org/10. 1111/j.15281167.2010.02645.x Epub 2010 Jun 7.

[67] Walker LE, Mirza N, Yip VLM, Marson AG, Pirmohamed M. Personalized medicine approaches in epilepsy. J Intern Med 2015 Feb;277(2):218-34. https://doi.org/10. 1111/joim.12322.

[68] Pisano T, Numis AL, Heavin SB, Weckhuysen S, Angriman M, Suls A, et al. Early and effective treatment of KCNQ2 encephalopathy. Epilepsia 2015 May;56(5):685-91. https://doi.org/10.1111/epi.12984 Epub 2015 Apr 16.

[69] Atkin TA, Maher CM, Gerlach AC, Gay BC, Antonio BM, Santos SC, et al. A comprehensive approach to identifying repurposed drugs to treat SCN8A epilepsy. Epilepsia 2018 Apr;59:802-13. https://doi.org/10.1111/epi.14037 Epub 2018 Mar 25.

[70] Sivapalarajah S, Krishnakumar M, Bickerstaffe H, Chan Y, Clarkson J, HampdenMartin A, et al. The prescribable drugs with efficacy in experimental epilepsies (PDE3) database for drug repurposing research in epilepsy. Epilepsia 2018 Feb;59(2): 492-501. https://doi.org/10.1111/epi.13994 Epub 2018 Jan 17.

[71] Pierson TM, Yuan H, Marsh ED, Fuentes-Fajardo K, Adams DR, Markello T, et al. GRIN2A mutation and early-onset epileptic encephalopathy: personalized therapy with memantine. Ann Clin Transl Neurol 2014 Mar 1;1(3):190-8.

[72] Milligan CJ, Li M, Gazina EV, Heron SE, Nair U, Trager C, et al. KCNT1 gain of function in 2 epilepsy phenotypes is reversed by quinidine. Ann Neurol 2014 Apr;75:581-90.

https://doi.org/10.1002/ana.24128 Epub 2014 Apr 14. 
[73] McTague A, Nair U, Malhotra S, Meyer E, Trump N, Gazina EV, et al. Clinical and molecular characterization of KCNT1-related severe early-onset epilepsy. Neurology 2018 Jan 2;90(1):e55-66. https://doi.org/10.1212/WNL. 00000000000047622017 Dec 1.

[74] Bearden D, Strong A, Ehnot J, DiGiovine M, Dlugos D, Goldberg EM. Targeted treatment of migrating partial seizures of infancy with quinidine. Ann Neurol 2014 Sep;76(3):457-61. https://doi.org/10.1002/ana.24229 Epub 2014 Jul 26.

[75] Mikati MA, Jiang YH, Carboni M, Shashi V, Petrovski S, Spillmann R, et al. Quinidine in the treatment of KCNT1-positive epilepsies. Ann Neurol 2015 Dec;78(6):995-9. https://doi.org/10.1002/ana.24520 Epub 2015 Nov 18.

[76] Fukuoka M, Kuki I, Kawawaki H, Okazaki S, Kim K, Hattori Y, et al. Quinidine therapy for West syndrome with KCNTI mutation: a case report. Brain Dev 2017 Jan;39(1):80-3. https://doi.org/10.1016/j.braindev.2016.08.002 Epub 2016 Aug 28.

[77] Abdelnour E, Gallentine W, McDonald M, Sachdev M, Jiang YH, Mikati MA. Does age affect response to quinidine in patients with KCNT1 mutations? Report of three new cases and review of the literature. Seizure 2019 May 6;55:1-3. https:// doi.org/10.1016/j.seizure.2019.04.014 pii: S1059-1311(19)30265-1. [Epub ahead of print].

[78] Ambrosino P, Soldovieri MV, Bast T, Turnpenny PD, Uhrig S, Biskup S, et al. De novo gain-of-function variants in KCNT2 as a novel cause of developmental and epileptic encephalopathy. Ann Neurol 2018 Jun;83(6):1198-204. https://doi.org/10.1002/ ana.25248.

[79] Chong PF, Nakamura R, Saitsu H, Matsumoto N, Kira R. Ineffective quinidine therapy in early onset epileptic encephalopathy with KCNT1 mutation. Ann Neurol 2016 Mar;79(3):502-3. https://doi.org/10.1002/ana.24598 [Epub 2016 Feb 12].

[80] Madaan P, Jauhari P, Gupta A, Chakrabarty B, Gulati S. A quinidine non responsive novel KCNT1 mutation in an Indian infant with epilepsy of infancy with migrating focal seizures. Brain Dev 2018 Mar;40(3):229-32. https://doi.org/10.1016/j. braindev.2017.09.008 [Epub 2017 Oct 14].

[81] Ko A, Youn SE, Kim SH, Lee JS, Kim S, Choi JR, et al. Targeted gene panel and genotype-phenotype correlation in children with developmental and epileptic encephalopathy. Epilepsy Res 2018 Mar;141:48-55. https://doi.org/10.1016/j. eplepsyres.2018.02.003 [Epub 2018 Feb 12].

[82] Mullen SA, Carney PW, Roten A, Ching M, Lightfoot PA, Churilov L, et al. Precision therapy for epilepsy due to KCNT1 mutations: a randomized trial of oral quinidine. Neurology 2018 Jan 2;90(1):e67-72. https://doi.org/10.1212/ WNL.0000000000004769 [Epub 2017 Dec 1].

[83] Delanty N, Cavalleri G. Genomics-guided precise anti-epileptic drug development. Neurochem Res 2017 Nov;42(11):3351. https://doi.org/10.1007/s11064-0172396-4.

[84] EpiPM Consortium. A roadmap for precision medicine in the epilepsies. Lancet Neurol 2015 Dec;14(12):1219-28. https://doi.org/10.1016/S1474-4422(15) 00199-4.

[85] Baker EM, Thompson CH, Hawkins NA, Wagnon JL, Wengert ER, Patel MK, et al. The novel sodium channel modulator GS-458967 (GS967) is an effective treatment in a mouse model of SCN8A encephalopathy. Epilepsia 2018 Jun;59(6):1166-76.

https://doi.org/10.1111/epi.14196 [Epub 2018 May 21]. 
[86] Quek AML, O'Toole O. Autoimmune epilepsy: the evolving science of neural autoimmunity and its impact on epilepsy management. Semin Neurol 2018 Jun; 38(3):290302. https://doi.org/10.1055/s-0038-1660860 [Epub 2018 Jul 16].

[87] Ravizza T, Vezzani A. Pharmacological targeting of brain inflammation in epilepsy: therapeutic perspectives from experimental and clinical studies. Epilepsia Open 2018 Dec;3(Suppl Suppl 2):133-42. https://doi.org/10.1002/epi4.12242 Published online 2018 Jul 16.

[88] Pitkänen A, Ekolle Ndode-Ekane X, Lapinlampi N, Puhakka N. Epilepsy biomarkers

— toward etiology and pathology specificity. Neurobiol Dis 2019 Mar;123:42-58.

https://doi.org/10.1016/j.nbd.2018.05.007 [Epub 2018 May 18].

[89] Song JM, Hahn J, Kim SH, Chang MJ. Efficacy of treatments for infantile spasms: a systematic review. Clin Neuropharmacol 2017 Mar/Apr;40(2):63-84. https:// doi.org/10.1097/WNF.0000000000000200.

[90] Mikati MA, Cornett KM. Therapy of infantile spasms: new opportunities and emerging challenges. Epilepsy Behav 2010;17(4):571-3. https://doi.org/10.1016/ j.yebeh.2009.12.018 [Epub 2010 Jan 25].

[91] Mikati MA, Lepejian GA, Holmes GL. Medical treatment of patients with infantile spasms. Clin Neuropharmacol 2002 Mar-Apr;25(2):61-70.

[92] Hani AJ, Mikati MA. Current and emerging therapies of severe epileptic encephalopathies. Semin Pediatr Neurol 2016;23(2):180-6. https://doi.org/10. 1016/j.spen.2016.06.001 [Epub 2016 Jun 3].

[93] Devinsky O, Cross JH, Laux L, Marsh E, Miller I, Nabbout R, et al. Trial of cannabidiol for drug-resistant seizures in the Dravet syndrome. N Engl J Med 2017 May 25;376(21):2011-20. https://doi.org/10.1056/NEJMoa1611618.

[94] Perucca E. Cannabinoids in the treatment of epilepsy: hard evidence at last? J Epilepsy Res 2017 Dec 31;7(2):61-76. https://doi.org/10.14581/jer.17012 eCollection 2017 Dec.

[95] Schoonjans A, Paelinck BP, Marchau F, Gunning B, Gammaitoni A, Galer BS, et al. Low-dose fenfluramine significantly reduces seizure frequency in Dravet syndrome: a prospective study of a new cohort of patients. Eur J Neurol 2017;24(2):309-14. https://doi.org/10.1111/ene.13195 [Epub 2016 Oct 28].

[96] Zaccara G, Schmidt D. Do traditional anti-seizure drugs have a future? A review of potential anti-seizure drugs in clinical development. Pharmacol Res 2016 Feb;104:38-48. https://doi.org/10.1016/j.phrs.2015.12.011 [Epub 2015 Dec 12].

[97] O'Callaghan FJK, Edwards SW, Alber FD, Cortina Borja M, Hancock E, Johnson AL, et al, International Collaborative Infantile Spasms Study (ICISS) investigators. Vigabatrin with hormonal treatment versus hormonal treatment alone (ICISS) for infantile spasms: 18-month outcomes of an open-label, randomised controlled trial. Lancet Child Adolesc Health 2018 Oct;2(10):715-25. https://doi.org/10. 1016/S2352-4642(18)30244-X [Epub 2018 Aug 29].

[98] Curatolo P, D'Argenzio L, Cerminara C, Bombardieri R. Management of epilepsy in tuberous sclerosis complex. Expert Rev Neurother 2008;8(3):457-67. https://doi.

org/10.1586/14737175.8.3.457. 
[99] van den Munckhof B, Alderweireld C, Davelaar S, van Teeseling HC, Nikolakopoulos S, Braun KPJ, et al. Treatment of electrical status epilepticus in sleep: clinical and EEG characteristics and response to 147 treatments in 47 patients. Eur J Paediatr Neurol 2018 Jan;22(1):64-71. https://doi.org/10.1016/j.ejpn.2017.08.006 [Epub 2017 Oct 26].

[100] Pera MC, Randazzo G, Masnada S, Dontin SD, De Giorgis V, Balottin U, et al. Intravenous methylprednisolone pulse therapy for children with epileptic encephalopathy. Funct Neurol 2015 Jul-Sep;30(3):173-9.

[101] Mikati MA, Saab R, Fayad MN, Choueiri RN. Efficacy of intravenous immunoglobulin in Landau-Kleffner syndrome. Pediatr Neurol 2002 April;26(4):298-300.

[102] Mikati MA, Kurdi R, El-Khoury Z, Rahi A, Raad W. Intravenous immunoglobulin therapy in intractable childhood epilepsy: open-label study and review of the literature. Epilepsy Behav 2010 Jan;17(1):90-4. https://doi.org/10.1016/j.yebeh. 2009.10.020 [Epub 2009 Dec 9].

[103] Geng J, Dong J, Li Y, Ni H, Jiang K, Shi LL, et al. Intravenous immunoglobulins for epilepsy. Cochrane Database Syst Rev 2017 July 4;7:CD008557. https://doi.org/10. 1002/14651858.CD008557.pub3.

[104] Fainberg N, Harper AN, Tchapyjnikov D, Mikati MA. Response to immunotherapy in a patient with Landau-Kleffner syndrome and GRIN2A mutation. Epileptic Disord 2016 Mar;18(1):97-100. https://doi.org/10.1684/epd.2016.0791.

[105] Mooneyham GC, Gallentine W, Van Mater H. Evaluation and management of autoimmune encephalitis: a clinical overview for the practicing child psychiatrist. Child Adolesc Psychiatr Clin N Am 2018;27(1):37-52. https://doi.org/10.1016/j. chc.2017.08.011 Epub 2017 Oct 20.

[106] Kenney-Jung DL, Vezzani A, Kahoud RJ, LaFrance-Corey RG, Ho ML, Muskardin TW, et al. Febrile infection-related epilepsy syndrome treated with anakinra. Ann Neurol 2016 Dec;80(6):939-45. https://doi.org/10.1002/ana.24806 [Epub 2016 Nov 14].

[107] Schulz A, Ajayi T, Specchio N, de Los Reyes E, Gissen P, Ballon D, et al, CLN2 Study Group. Study of intraventricular cerliponase alfa for CLN2 disease. N Engl J Med 2018;378(20):1898-907 [doi: 10.1056 PMID: 29688815].

[108] Liu YH, Wang XL, Deng YC, Zhao G. Levetiracetam-associated aggravation of myoclonic seizure in children. Seizure 2012 Dec;21(10):807-9. https://doi.org/ 10.1016/j.seizure.2012.08.008 [Epub 2012 Sep 16].

[109] Polster T. Individualized treatment approaches: fenfluramine, a novel antiepileptic medication for the treatment of seizures in Dravet syndrome. Epilepsy Behav 2019 Feb;91:99-102 [doi: 10.1016 PMID: 30269941]. 